\title{
Dodecanuclear 3d/4f-Metal Clusters with a 'Star of David' Topology: Single-Molecule Magnetism and Magnetocaloric Properties
}

\author{
Dimitris I. Alexandropoulos, ${ }^{a}$ Luis Cunha-Silva, ${ }^{c}$ Giulia Lorusso, ${ }^{d}$ Marco Evangelisti, ${ }^{d}$ Jinkui Tang ${ }^{* b}$ and \\ Theocharis C. Stamatatos*a
}

\author{
${ }_{5}$ Received (in $\left.X X X, X X X\right) X$ th $X X X X X X X X X 20 X X$, Accepted $X$ th $X X X X X X X X X 20 X X$ \\ DOI:
}

A family of interwoven molecular inorganic knots, shaped like the 'Star of David', was prepared by the employment of naphthalene-2,3-diol in $3 d / 4 f-m e t a l$ cluster chemistry; the 10 isoskeletal dodecanuclear compounds exhibit slow relaxation of the magnetization and magnetocaloric properties, depending on the metal ion.

The last three decades or so molecular chemistry has received a tremendous attention due to the potential applications of 15 molecular nanoscale materials in both applied and fundamental areas of research. In addition to their interesting physicochemical properties, molecular organic and inorganic chemistry has supplied literature with aesthetically beautiful and complex structures such as highly-symmetric rotaxanes ${ }^{1}$ 20 and catenanes, ${ }^{2}$ molecular nanocars and machines, ${ }^{3}$ and polynuclear coordination cluster compounds. ${ }^{4}$ Undoubtedly, it is really fascinating for everyone to come across molecular structures reminiscent to the complicated Archimedean and Platonic solids, , $^{\text {a }}$ "molecular Meccanos", 5 b or even to daily 25 life geometric shapes, such as triangles, wheels, stars, etc. In addition to the synthetic challenges and aesthetic appeal associated with such architectures, current efforts are also driven by the desire to produce multifunctional systems.

From an inorganic chemistry viewpoint, the choice of 30 metal(s) and organic chelate(s) is of significant importance because they do not only dictate the structures and topologies but also the resulting properties and applications. In the field of molecular magnetism, polynuclear heterometallic 3d/4fmetal cluster complexes are excellent candidates for single35 molecule magnetism ${ }^{6}$ and/or magnetic refrigeration ${ }^{7}$ properties when the paramagnetic metal ions are highly anisotropic (i.e., Dy ${ }^{\mathrm{III}}$ ) or high-spin and isotropic (i.e., $\mathrm{Gd}^{\mathrm{III}}$ ), respectively. Although there are numerous 3d/4f-metal cluster compounds reported to date, ${ }^{8}$ there is still a thirst for the 40 synthesis of new, structurally notable complexes and for building-up families of high-nuclearity, isoskeletal transition metal-lanthanide clusters, where the 3d-metal ion will be deliberately replaced in the polymetallic motif without breaking the core structure but instead altering the physical 45 (magnetic, optical, etc.) properties. Families of previously reported isoskeletal 3d/4f-metal complexes with a variety of different 3d-metals are restricted to few oligonuclear compounds (i.e., dimers, ${ }^{9}$ trimers, ${ }^{10}$ and tetramers ${ }^{11}$ ) with known structural motifs such as triangles and butterflies.
50 In this work, we report the first family of isoskeletal, highnuclearity $\left[\{3 \mathrm{~d}\}_{6}\{4 \mathrm{f}\}_{6}\right]$ clusters with a unique 'Star of David' topology resulting from the use of naphthalene-2,3-diol (ndH $\mathrm{H}_{2}$ as chelating/bridging ligand. ${ }^{12 a}$ The described compounds exhibit a variety of different magnetic behaviors, 55 from slow relaxation of the magnetization to magnetic refrigeration, depending on the degree of magnetic anisotropy involved, ${ }^{8 a}$ as determined by the transition metal and lanthanide ion used. The reaction of equimolar amounts of $\mathrm{M}\left(\mathrm{NO}_{3}\right)_{2} \cdot 6 \mathrm{H}_{2} \mathrm{O}$ and $\mathrm{Ln}\left(\mathrm{NO}_{3}\right)_{3} \cdot 6 \mathrm{H}_{2} \mathrm{O}\left(\mathrm{M}=\mathrm{Co}^{\mathrm{II}}, \mathrm{Ni}^{\mathrm{II}}, \mathrm{Zn}^{\mathrm{II}} ; \mathrm{Ln}=\right.$ ${ }_{60} \mathrm{Gd}^{\mathrm{III}}$, Dy $\left.{ }^{\mathrm{III}}\right)$ with two equivalents of each $\mathrm{ndH}_{2}$ and $\mathrm{NEt}_{3}$ in $\mathrm{MeCN} / \mathrm{Et}_{2} \mathrm{O}$ gave the dodecanuclear compounds $\left[\mathrm{M}_{6} \mathrm{Ln}_{6}\left(\mathrm{NO}_{3}\right)_{6}(\mathrm{nd})_{12}\left(\mathrm{H}_{2} \mathrm{O}\right)_{\mathrm{x}}(\mathrm{MeCN})_{\mathrm{y}}\right](\mathrm{x}=2$ and $\mathrm{y}=12$ for 1-Co ${ }_{6} \mathrm{Gd}_{6}, 2-\mathrm{Co}_{6} \mathrm{Dy}_{6}$ and $3-\mathrm{Ni}_{6} \mathrm{Gd}_{6} ; \mathrm{x}=10$ and $\mathrm{y}=4$ for 4-Ni ${ }_{6} \mathrm{Dy}_{6}$ and $6-\mathrm{Zn}_{6} \mathrm{Dy}_{6} ; \mathrm{x}=6$ and $\mathrm{y}=8$ for $5-\mathrm{Zn}_{6} \mathrm{Gd}_{6}$, ) in 65 very good yields $(>65 \%) . \dagger$ The chemical and structural identities of the reported compounds were confirmed by single-crystal X-ray crystallography (complete data sets for $\mathbf{1}$, $3,4,5,6$, and adequate unit cell indexing for 2), elemental analyses $(\mathrm{C}, \mathrm{H}, \mathrm{N})$, powder XRD analyses, and IR spectral 70 comparison. $\dagger$

All complexes 1-6 possess similar structures (Fig. 1, top) reminiscent to a 'Star of David' topology (Fig. 1, bottom left), which is unprecedented in metal cluster chemistry. ${ }^{12 b}$ The structures differ only in the divalent 3d-metal ion and the 75 number of terminally bound $\mathrm{H}_{2} \mathrm{O}$ and MeCN molecules. Representative complex 1 (Fig. 1, top) consists of an internal non-planar ring of six $\mathrm{Gd}^{\mathrm{III}}$ ions, templated around a $\eta^{2}: \eta^{2}: \eta^{2}: \mu_{6}-\mathrm{NO}_{3}{ }^{-}$ion ${ }^{13}$ locked at the center of the structure. The $\mathrm{Gd}_{6}$ unit is further linked to a planar ring of six external ${ }_{80} \mathrm{Co}^{\mathrm{II}}$ ions through the $\mu_{3}-\mathrm{OR}$ arms of six $\eta^{3}: \eta^{3}: \mu_{5} \mathrm{nd}^{2-}$ ligands. Additional bridging between the $\mathrm{Co}^{\mathrm{II}}$ and $\mathrm{Gd}^{\mathrm{III}}$ ions is provided by $12 \mu$-OR groups from six $\eta^{2}: \eta^{2}: \mu_{3} \mathrm{nd}^{2-}$ ligands (Scheme S1). The complete $\left[\mathrm{Co}_{6} \mathrm{Gd}_{6}\left(\mu_{6}-\mathrm{NO}_{3}\right)\left(\mu_{3}-\mathrm{OR}\right)_{12}(\mu-\right.$ $\left.\mathrm{OR})_{12}\right]^{5+}$ core (Fig. 2) has a rare $D_{3 \mathrm{~d}}$ symmetry which is 85 crystallographically imposed. The remaining $\mathrm{NO}_{3}{ }^{-}$groups are acting as bidentate chelating ligands to the 4f-metal ions; all $\mathrm{Co}^{\mathrm{II}}$ atoms are six-coordinate with distorted octahedral geometries and all the $\mathrm{Gd}^{\mathrm{III}}$ atoms are nine-coordinate with spherical capped square antiprismatic geometries (program 90 SHAPE; ${ }^{14}$ CShM values $=1.37,1.45,2.05$, see Fig. S1). The 'Star of David' is a six-pointed metal star, made of two equilateral $\mathrm{Co}_{3}$ triangles $\left(\mathrm{Co}-\mathrm{Co}-\mathrm{Co}=60^{\circ}\right.$ ) that cross at six places, the six $\mathrm{Gd}^{\mathrm{III}}$ atoms. The space-filling representation 
(Fig. 1, bottom right) shows that $\mathbf{1}$ has a beautiful spherical structure with distances across the three corners of $\sim 25 \AA$, as defined by the longest $\mathrm{C} \cdots \mathrm{C}$ distance of the externally bound $\mathrm{nd}^{2-}$ ligands. Finally, the reported compounds join the family 5 of $\left\{\mathrm{M}_{6} \operatorname{Ln}_{6}\right\}$ clusters with a Wells-Dawson ${ }^{15}$ and octahedronin-octahedron ${ }^{16}$ topologies.
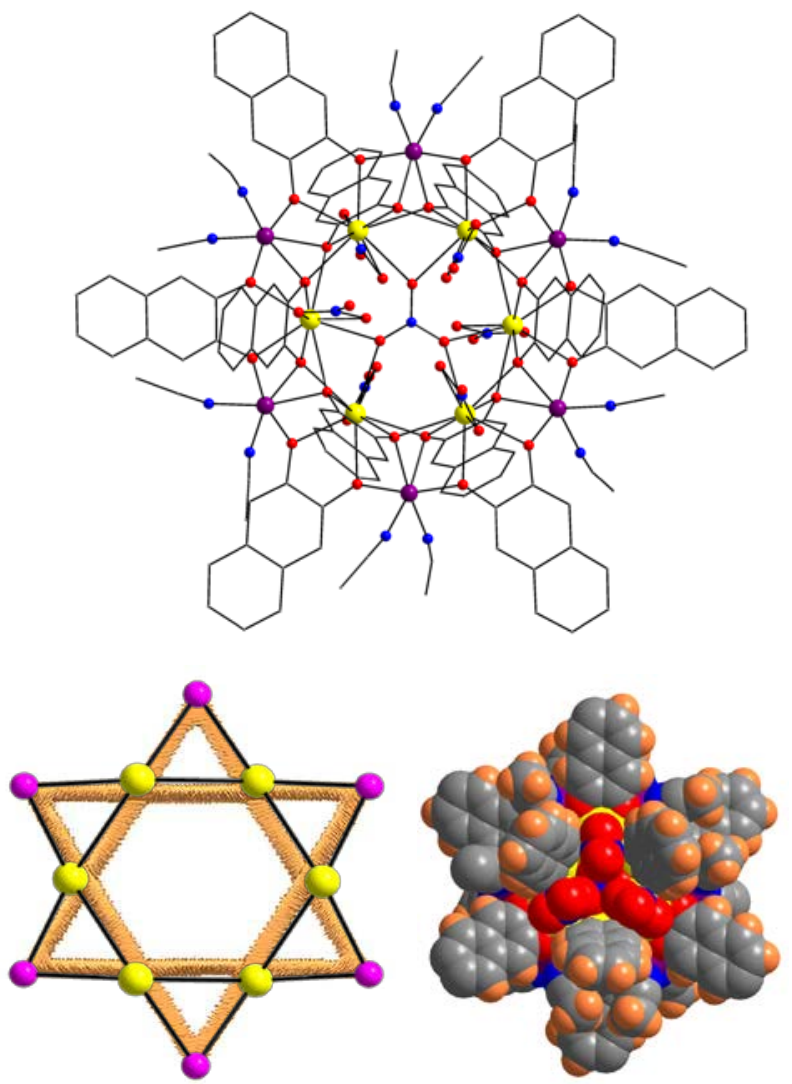

Fig. 1 Complete structure of 1 (top), the $\mathrm{Co}_{6} \mathrm{Gd}_{6}$ 'Star of David' topology 10 (enumerated as 2,4M12-1) ${ }^{17}$, with the black lines indicating the metal $\cdots$ metal vectors (bottom, left), and a space-filling representation of $\mathbf{1}$ (bottom, right). $\mathrm{H}$ atoms are either omitted for clarity or shown in orange. Color scheme: $\mathrm{Co}^{\mathrm{II}}$ purple, $\mathrm{Gd}^{\mathrm{III}}$ yellow, O red, $\mathrm{N}$ blue, $\mathrm{C}$ dark gray.

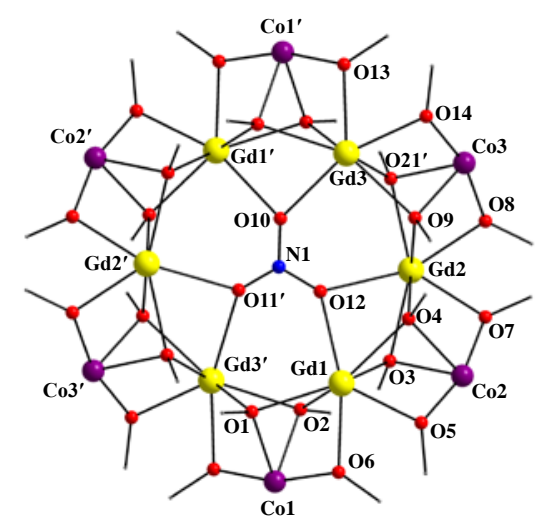

15 Fig. 2 Partially-labeled core of $\mathbf{1}$. Color scheme as in Fig. 1. Symmetry operation for the primed atoms: $1-x,-y+1,-z+1$.

Solid-state direct-current (dc) magnetic susceptibility $\left(\chi_{\mathrm{M}}\right)$ data on dried and analytically-pure samples of 1-6 were collected in the 2.0-300 $\mathrm{K}$ range in an applied field of $0.1 \mathrm{~T}$, 20 and are plotted as $\chi_{\mathrm{M}} T$ vs $T$ in Fig. S2. The experimental $\chi_{\mathrm{M}} T$ values at $300 \mathrm{~K}$ for all complexes are in excellent agreement with the theoretical ones expected for $6 \mathrm{HS}(S=3 / 2, g=2)$ $\mathrm{Co}^{\mathrm{II}}$ and $6 \mathrm{Gd}^{\mathrm{III}}$ or $6 \mathrm{Dy}^{\mathrm{III}}$ (58.50 or $96.27 \mathrm{~cm}^{3} \mathrm{Kmol}^{-1}$ ), $6 \mathrm{Ni}^{\mathrm{II}}$ $(S=1, g=2.2)$ and $6 \mathrm{Gd}^{\mathrm{III}}$ or $6 \mathrm{Dy}^{\mathrm{III}}$ (54.51 or 92.28 $\left.{ }_{25} \mathrm{~cm}^{3} \mathrm{Kmol}^{-1}\right)$, and $6 \mathrm{Gd}^{\mathrm{III}}\left({ }^{8} \mathrm{~S}_{7 / 2}, S=7 / 2, L=0, g=2\right)$ or $6 \mathrm{Dy}^{\mathrm{III}}$ $\left({ }^{6} \mathrm{H}_{15 / 2}, S=5 / 2, L=5, g=4 / 3\right)\left(47.25\right.$ or $\left.85.02 \mathrm{~cm}^{3} \mathrm{Kmol}^{-1}\right)$ non-interacting ions. In the $\sim 70-300 \mathrm{~K}$ regime, the magnetic response of 1-6 is essentially identical for all complexes, with the $\chi_{\mathrm{M}} T$ products remaining almost constant suggesting very 30 weak to negligible magnetic exchange interactions between the metal centers. At temperatures below $\sim 60 \mathrm{~K}$, the $\chi_{\mathrm{M} T}$ product of $\mathrm{Zn}_{6} \mathrm{Gd}_{6}$ (magnetically a homo-lanthanide $\mathrm{Gd}_{6}$ compound) steadily decreases, indicative of weak antiferromagnetic exchange interactions between the $6 \mathrm{Gd}^{\text {III }}$ 35 centers propagated by the alkoxido arms of $\mathrm{nd}^{2-}$ and likely the $\mathrm{O}$ atoms of the $\mu_{6}$-bridging $\mathrm{NO}_{3}{ }^{-}$group. The $\chi_{\mathrm{M}} T$ products for the corresponding $\mathrm{Co}_{6} \mathrm{Gd}_{6}$ (1) and $\mathrm{Ni}_{6} \mathrm{Gd}_{6}$ (3) clusters are similar in decreasing with decreasing $T$ down to $10 \mathrm{~K}$, albeit 1 shows a $\chi_{\mathrm{M}} T$ rise in the $10-3.5 \mathrm{~K}$ in contrast to the $\chi_{\mathrm{M}} T$ of $\mathbf{3}$ 40 which keeps decreasing. As corroborated by the specific heat experiments discussed below, the magnetic behavior of $\mathbf{1}$ can be described by the sum of two contributions: an outer ferromagnetic $\mathrm{Co}_{6}$ 'shell', which is responsible for the $\chi_{\mathrm{M}} T$ rise, and an antiferromagnetic inner $\mathrm{Gd}_{6}$ core. Since the 45 occupied orbitals of $\mathrm{Gd}^{\mathrm{III}}$ are quite centered, we can reasonably approximate these two contributions as magnetically independent. For all the $\mathrm{M}_{6} \mathrm{Dy}_{6}$ analogues, the low temperature $(<60 \mathrm{~K})$ magnetic behavior is very similar, with the $\chi_{\mathrm{M}} T$ products rapidly decreasing down to $2 \mathrm{~K}$ 50 indicating the presence of predominant antiferromagnetic exchange interactions between the metal centers and/or depopulation of the excited $M_{J}$ states. Magnetization $(M)$ vs field $(H)$ studies for the $\mathrm{M}_{6} \mathrm{Gd}_{6}$ analogues from 2 to $10 \mathrm{~K}$ show a continuous increase of $M$ as $H$ increases and a trend ${ }_{55}$ for saturation at the maximum possible $S$ values (Fig. S3). In contrast, for the $\mathrm{M}_{6} \mathrm{Dy}{ }_{6}$ members the magnetization shows a steady increase with increasing $H$ but does not saturate, indicative of the presence of magnetic anisotropy and/or population of low-lying excited states (Fig. S4).

60 Given the interest in $3 \mathrm{~d} / \mathrm{Gd}$-metal clusters as lowtemperature magnetic coolers, ${ }^{7,15}$ we decided to investigate the magnetocaloric properties of the Gd-containing complexes 1 and 5. In the top panels of Fig. 3, we report the specific heat, normalized to the gas costant $R$, for $\mathrm{Zn}_{6} \mathrm{Gd}_{6}$ (5) and

${ }_{65} \mathrm{Co}_{6} \mathrm{Gd}_{6}$ (1), respectively. Since the two compounds are isostructural, we obtain the same lattice contribution, Clatt, which can be described by the Debye model (dashed lines), with a Debye temperature $\theta_{D}=29.6 \mathrm{~K}$. From the magnetic contribution, $C_{\mathrm{m}}$, obtained by subtracting $C_{\text {latt }}$ to the total heat 70 capacity, we estimated the $T$-dependence of the magnetic entropy, $S_{\mathrm{m}}(T)=\int C_{\mathrm{m}}(T) / T \mathrm{~d} T$ for both compounds (bottom panels of Fig. 3). For 5, we compare the experimental data with the contributions (solid lines in Fig. 3) that result by summing together the Schottky curves arising from the field75 split levels of $6 \mathrm{Gd}^{\mathrm{III}}$ independent spins. It can be seen that the $\mathrm{Gd}^{\mathrm{III}}$ spins are weakly correlated, since the applied field gradually promotes a large decoupling, yielding thus a good agreement. Besides, the weak interactions permit $S_{\mathrm{m}}(T)$ to 
reach the maximum entropy value per mole involved, i.e., $6 R \ln \left(2 S_{\mathrm{Gd}}+1\right) \cong 12.5 R$. For 1 , assuming the ferromagnetic interactions between the 6 peripheral $\mathrm{Co}^{\mathrm{II}}$ ions to be strong enough to yield a well-defined $S=9$ state, one would expect

${ }_{5} C_{\mathrm{m}}$ to be well described by the sum of Schottky contributions (solid lines of Fig. 3) for 6 independent $\mathrm{Gd}^{\mathrm{III}}$ spins and a $S=9$ net spin, as indeed observed. Ordering of these $S=9$ spins within each $\mathrm{Co}_{6} \mathrm{Gd}_{6}$ molecule yields an entropy change $R \ln (2 S+1) \cong 2.9 R$. Therefore, $S_{\mathrm{m}}(T)$ is seen to gradually tend 10 to $(12.5+2.9) R=15.4 R$ (Fig. 3$)$.

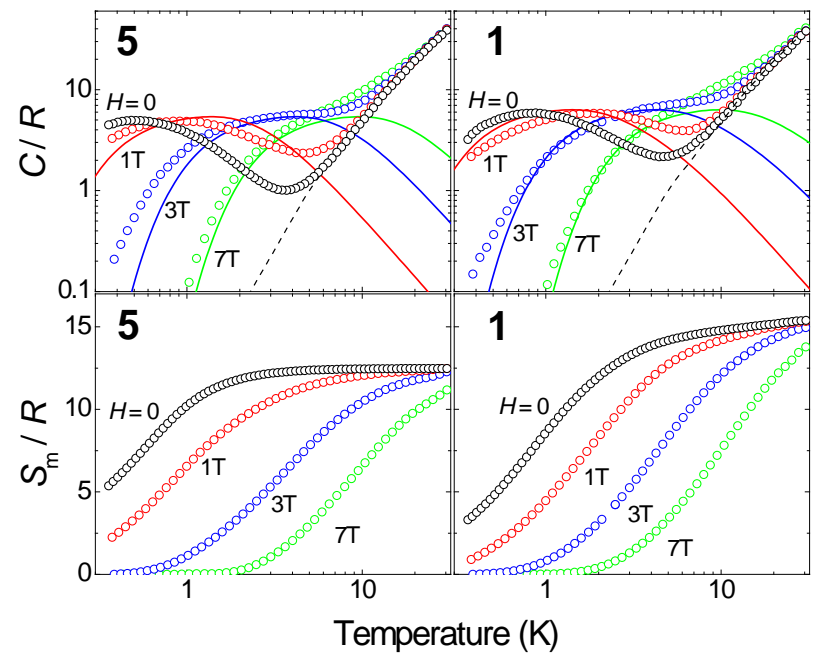

Fig. 3 (top) Temperature-dependence of the specific heat, normalized to the gas constant $R$, for $\mathrm{Zn}_{6} \mathrm{Gd}_{6}$ (left) and $\mathrm{Co}_{6} \mathrm{Gd}_{6}$ (right) at the indicated fields. Solid thick lines are the sums of the calculated Schottky 15 contributions (see text); dashed line is the fitted lattice contribution. (bottom) Temperature-dependence of the magnetic entropy, normalized to the gas constant $R$, as obtained from the specific heat data.

Figure 4 shows the magnetic entropy changes, $\Delta S_{\mathrm{m}}$, for $\mathrm{Zn}_{6} \mathrm{Gd}_{6}$ (5) and $\mathrm{Co}_{6} \mathrm{Gd}_{6}(\mathbf{1})$, as derived from specific heat $(C$, 20 Fig. 3) and magnetization ( $M$, Fig. S3) data, following known data analysis procedures. ${ }^{18}$ The nice agreement between the so-differently obtained sets of data proves the validity of our results. For 5, the experimental $-\Delta S_{\mathrm{m}}$ approaches the maximum entropy value per mole $\left(12.5 R=25.1 \mathrm{~J} \mathrm{~kg}^{-1} \mathrm{~K}^{-1}\right)$, 25 reaching $11.6 R$, equivalent to $22.8 \mathrm{~J} \mathrm{~kg}^{-1} \mathrm{~K}^{-1}$, for the $\mu_{0} \Delta H=7$ $\mathrm{T}$ maximum field change, at $T=2.0 \mathrm{~K}$. For 1 , the additional $\mathrm{Co}^{\mathrm{II}}$ magnetic centers, thus the relatively larger magnetic density, promote an overall larger magnetocaloric effect with $-\Delta S_{\mathrm{m}}$ reaching $12.0 R=23.7 \mathrm{~J} \mathrm{~kg}^{-1} \mathrm{~K}^{-1}$ for $\mu_{0} \Delta H=7 \mathrm{~T}$, at $T=$ ${ }_{30} 2.7 \mathrm{~K}$. Note that the stronger interactions in $\mathbf{1}$, combined with the magnetic anisotropy of the $\mathrm{Co}^{\mathrm{II}}$ ions, shift the $-\Delta S_{\mathrm{m}}$ maxima towards somewhat higher temperatures than in $\mathbf{5}^{18,19}$ The observed magnetocaloric effect for $\mathrm{Zn}_{6} \mathrm{Gd}_{6}$ and $\mathrm{Co}_{6} \mathrm{Gd}_{6}$ has a similar strength with that already reported for other 35 molecular cluster complexes based on $\mathrm{Zn}(\mathrm{II}) / \mathrm{Gd}(\mathrm{III})$ and Co(II)/Gd(III). ${ }^{18}$

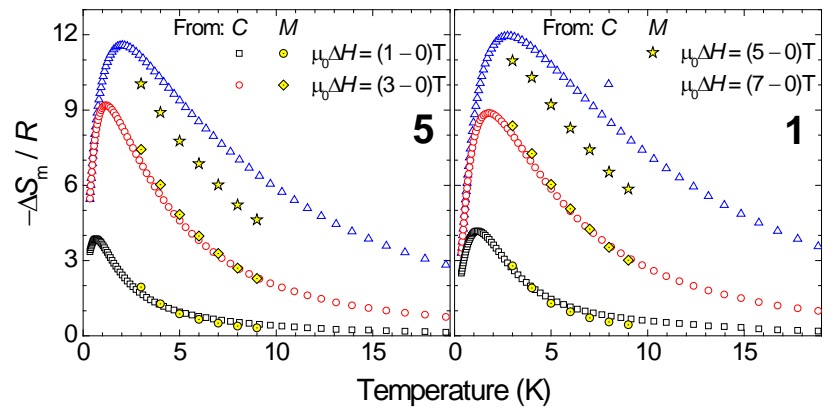

Fig. 4 Magnetic entropy changes, normalized to the gas constant $R$, for $\mathrm{Zn}_{6} \mathrm{Gd}_{6}$ (left) and $\mathrm{Co}_{6} \mathrm{Gd}_{6}$ (right), as obtained from specific heat $(C)$ and 40 magnetization $(M)$ experiments for the indicated applied field changes.

Alternating-current (ac) magnetic susceptibility studies have also been carried out in order to investigate the magnetization dynamics of 1-6 in the absence of an external dc magnetic field. Only the compounds with the most ${ }_{45}$ prominent magnetic anisotropies, that are the $\mathrm{Ni}_{6} \mathrm{Dy}_{6}$ (Fig. S5) and $\mathrm{Zn}_{6} \mathrm{Dy} 6$ (Fig. 5) analogues, showed frequency-dependent out-of-phase $\chi^{\prime \prime} \mathrm{M}$ tails at temperatures below $\sim 3$ and $\sim 5 \mathrm{~K}$, respectively. This behavior, which mainly originates from single-ion anisotropy effects of the individual Dy ${ }^{\mathrm{III}}$ Kramers 50 ions, ${ }^{6}$ is a signature of slow relaxation of the magnetization that is frequently observed in high-nuclearity single-molecule magnets. ${ }^{4,6,8}$

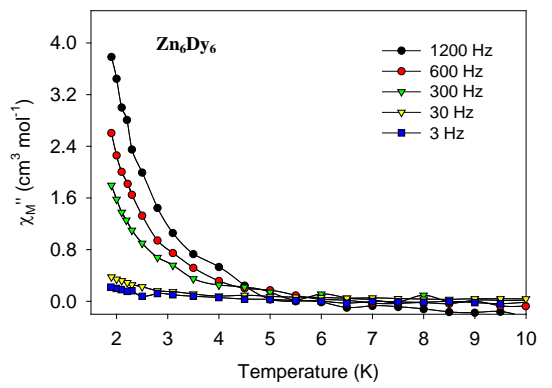

Fig. 5 Frequency-dependent out-of-phase $\left(\chi_{M}^{\prime \prime}\right)$ ac susceptibility signals 55 for $\mathrm{Zn}_{6} \mathrm{Dy}_{6}$ in a $3 \mathrm{G}$ oscillating field.

In conclusion, we have shown that the self-assembly reaction of various divalent transition metals and lanthanides with the bulky naphthalene-2,3-diol ligand has led to the first dodecanuclear 3d/4f-metal clusters with a beautiful 'Star of ${ }_{60}$ David' topology. The molecular skeleton resembles a hexagram which is flexible enough to accommodate many different $\mathrm{M}^{\mathrm{II}}$ and $\mathrm{Ln}^{\mathrm{III}}$ ions, thus leading to compounds with a variety of physical behaviors, from magnetic refrigeration to slow relaxation of the magnetization. Finally, the reported ${ }_{65}$ compounds are distinctly different than the $\mathrm{Mn}_{4} \mathrm{Ln}$ clusters of Coucouvanis et. al., ${ }^{20}$ obtained from the use of catechol chelate which is structurally similar to $\mathrm{ndH}_{2}$. Work in progress includes the extension of this family of clusters to all posibble $\mathrm{M}^{\mathrm{II}}{ }_{6} \mathrm{Ln}_{6}$ members, their photophysical characterization, and $a b$ 70 initio calculations for the $\mathrm{Zn}_{6} \mathrm{Dy}_{6}$ in a quest for important magnetic phenomena such as the toroidal magnetic moment.

\section{Acknowledgements}

This work was supported by Brock University, NSERC-DG 
and ERA (to Th.C.S), the Ontario Trillium Foundation (graduate scholarship to D.I.A), the Fundação para a Ciência e a Tecnologia (FCT, Portugal) for financial support to REQUIMTE/LAQV (UID/QUI/50006/2013), the European 5 Synchrotron Radiation Facility (Grenoble, France) for granting access time to the the Swiss-Norwegian BM01a beamline under the $\mathrm{CH}-3613$ and $\mathrm{CH}-3849$ research proposals, MINECO (FEDER-MAT2012-38318-C03 to M.E and postdoctoral contract to G.L), and the National Natural ${ }_{10}$ Science Foundation of China (grants 21371166, 21331003 and 21221061 to J.T).

\section{Notes and references}

a Department of Chemistry, Brock University, St. Catharines, Ontario, L2S3A1, Canada. Tel: (+1)-905-688-5550 Ext. 3400; E-mail: 15 tstamatatos@brocku.ca

${ }^{b}$ State Key Laboratory of Rare Earth Resource Utilization, Changchun Institute of Applied Chemistry, Chinese Academy of Sciences, Changchun 130022, P. R. China.

${ }^{c}$ REQUIMTE / LAQV \& Department of Chemistry and Biochemistry, 20 Faculty of Sciences, University of Porto, 4169-007 Porto, Portugal.

d Instituto de Ciencia de Materiales de Aragón (ICMA) and Departamento de Física de la Materia Condensada, CSIC-Universidad de Zaragoza, 50009 Zaragoza, Spain.

† Electronic Supplementary Information (ESI) available: Full synthetic 25 and crystallographic discussion, structural figures, various plots and magnetic data. See DOI: 10.1039/b000000x/

1 (a) C.- F. Lee, D. A. Leigh, R. G. Pritchard, D. Schultz, S. J. Teat, G. A. Timco and R. E. P. Winpenny, Nature, 2009, 458, 314; (b) A. Altieri, G. Bottari, F. Dehez, D. A. Leigh, J. K. Y. Wong and F. Zerbetto, Angew. Chem. Int. Ed., 2003, 42, 2296.

2 (a) D. A. Leigh, R. G. Pritchard and A. J. Stephens, Nature Chem., 2014, 6, 978; (b) J.- P. Sauvage and C. Dietrich-Buchecker in "Molecular catenanes, rotaxanes and knots: a journey through the world of molecular topology", Wiley-VCH, 1999.

353 (a) V. Balzani, A. Credi, F. M. Raymo and J. F. Stoddart, Angew. Chem. Int. Ed., 2000, 39, 3348; (b) J. D. Badjic, V. Balzani, A. Credi, S. Silvi and J. F. Stoddart, Science, 2004, 303, 1845; (c) J. Shirai, A. J. Osgood, Y. Zhao, K. F. Kelly and J. M. Tour, Nano Lett., 2005, 5, 2330.

404 For some representative, complex structures, see: (a) A. J. Tasiopoulos, A. Vinslava, W. Wernsdorfer, K. A. Abboud and G. Christou, Angew. Chem. Int. Ed., 2004, 43, 2117; (b) G. F. S. Whitehead, F. Moro, G. A. Timco, W. Wernsdorfer, S. J. Teat and R. E. P. Winpenny, Angew. Chem. Int. Ed., 2013, 125, 10116; (c) R. T.

45 W. Scott, S. Parsons, M. Murugesu, W. Wernsdorfer, G. Christou and E. K. Brechin, Angew. Chem. Int. Ed., 2005, 44, 6540; (d) E. E. Moushi, C. Lampropoulos, W. Wernsdorfer, V. Nastopoulos, G. Christou and A. J. Tasiopoulos, J. Am. Chem. Soc., 2010, 132, 16146.

5 (a) Y. Zheng, Q.- C. Zhang, L.- S. Long, R.- B. Huang, A. Müller, J. $50 \quad$ Schnack, L.- S. Zheng and Z. Zheng, Chem. Commun., 2013, 49, 36; (b) J. Fielden and L. Cronin, in "Encyclopedia of Supermolecular Chemistry”, Taylor \& Francis, 2005.

6 D. Gatteschi, R. Sessoli and J. Villain, in Molecular Nanomagnets, 2006 (Oxford University Press: Oxford).

557 (a) J. W. Sharples and D. Collison, Polyhedron 2013, 54, 91 ; (b) M. Evangelisti, Molecule-Based Magnetic Coolers: Measurement, Design and Application, in Molecular Magnets: Physics and Applications, J. Bartolomé, F. Luis, J. F. Fernández, (Eds) 2014, Springer, Verlag Berlin Heidelberg, 365-387.

608 Representative examples: (a) G. Karotsis, S. Kennedy, S. J. Teat, C. M. Beavers, D. A. Fowler, J. J. Morales, M. Evangelisti, S. J. Dalgarno and E. K. Brechin, J. Am. Chem. Soc., 2010, 132, 12983; (b) X.- J. Kong, Y.- P. Ren, W.- X. Chen, L.-S. Long, Z. Zheng, R.B. Huang and L.- S. Zheng, Angew. Chem. Int. Ed., 2008, 47, 2398;

65 (c) L. R. Piquer and E. C. Sañudo, Dalton Trans., 2015, 44, 8771; (d) K. Liu, W. Shi and P. Cheng, Coord. Chem. Rev., 2015, 289-290, 74.
9 A. N. Georgopoulou, R. Adam, C. P. Raptopoulou, V. Psycharis, R. Ballesteros, B. Abarca and A. K. Boudalis, Dalton Trans., 2010, 39, 5020.

7010 C. G. Efthymiou, A. N. Georgopoulou, C. Papatriantafyllopoulou, A. Terzis, C. P. Raptopoulou, A. Escuer and S. P. Perlepes, Dalton Trans., 2010, 39, 8603.

11 (a) S. M. T. Abtab, M. Maity, K. Bhattacharya, E. C. Sanudo and M. Chaudhury, Inorg. Chem., 2012, 51, 10211; (b) M. Holynska and M. Korabik, Eur. J. Inorg. Chem., 2013, 5469; (c) Z.- S. Meng, F.- S. Guo, J.- L. Liu, J.- D. Leng and M.- L. Tong, Dalton Trans., 2012, 41, 2320; (d) K. Griffiths, C. W. D. Gallop, A. Abdul-Sada, A. Vargas, O. Navarro and G. E. Kostakis, Chem. Eur. J., 2015, 21, 6358.

8012 (a) For the only previously reported metal cluster with the group $\mathrm{nd}^{2-}$, see: D. I. Alexandropoulos, A. Fournet, L. Cunha-Silva, A. M. Mowson, V. Bekiari, G. Christou and Th. C. Stamatatos, Inorg. Chem., 2014, 53, 5420; (b) For a Dy $y_{12}$ wheel compound of six vertexsharing triangles, see: L. Zhao, S. Xue and J. Tang, Inorg. Chem., 2012, 51, 5994.

13 Compound with $\mu_{6}-\mathrm{NO}_{3}{ }^{-}$ion: J.- L. Liu, Y.- C. Chen, Q.- W. Li, S. Gomez-Coca, D. Aravena, E. Ruiz, W.- Q. Lin, J.- D. Leng and M.L. Tong, Chem. Commun., 2013, 49, 6549.

14 S. Alvarez, P. Alemany, D. Casanova, J. Cirera, M. Llunell and D. Avnir, Coord. Chem. Rev., 2005, 249, 1693.

15 (a) E. M. Pineda, F. Tuna, Y.- Z. Zheng, R. E. P. Winpenny and E. J. L. McInnes, Inorg. Chem., 2013, 52, 13702; (b) Y.- Z. Zheng, M. Evangelisti and R. E. P. Winpenny, Angew. Chem. Int. Ed., 2011, 50, 3692; (c) E. M. Pineda, F. Tuna, Y.- Z. Zeng, S. J. Teat, R. E. P. 95 Winpenny, J. Schnack and E. J. L. McInnes, Inorg. Chem., 2014, 53, 3032.

16 A. S. Dinca, A. Ghirri, A. M. Madalan, M. Affronte and M. Andruh, Inorg. Chem., 2012, 51, 3935.

17 For a fantastic review on the topological analysis of cluster compounds, see: G. E. Kostakis, V. A. Blatov and D. M. Proserpio, Dalton Trans., 2012, 41, 4634.

18 For Zn/Gd and Co/Gd molecular coolants, see: (a) W. Sethi, S. Sanz, K. S. Pedersen, M. A. Sorensen, G. S. Nichol, G. Lorusso, M. Evangelisti, E. K. Brechin and S. Piligkos, Dalton Trans., 2015, 44, 10315; (b) J. Ruiz, G. Lorusso, M. Evangelisti, E. K. Brechin, S. J. A. Pope and E. Colacio, Inorg. Chem., 2014, 53, 3586; (c) T. N. Hooper, J. Schnack, S. Piligkos, M. Evangelisti and E. K. Brechin, Angew. Chem. Int. Ed., 2012, 51, 4633; (d) Y.- Z. Zheng, M. Evangelisti, F. Tuna and R. E. P. Winpenny, J. Am. Chem. Soc., 2012, 134, 1057; (e) E. M. Pineda, F. Tuna, R. G. Pritchard, A. C. Regan, R. E. P. Winpenny and E. J. L. McInnes, Chem. Commun., 2013, 49, 3522.

19 M. Evangelisti and E. K. Brechin, Dalton Trans., 2010, 39, 4672.

20 R. A. Reynolds, III and D. Coucouvanis, J. Am. Chem. Soc., 1998, 120, 209. 